\title{
EFSUMB Upcoming webinars
}

\section{EFSUMB WEBINAR 17 September 2020, 11.00 CEST CEUS for the management of focal liver disease

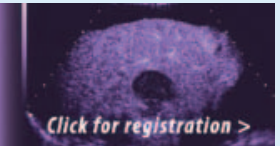

- clinical value of CEUS in ggllbladder disease Xiang Fei

- CEUS diagnosis of new hepatic nodules in patients with colorectal cancer during chemotherapy Guang-Jian Liu

- Combined application of navigation and contrast-enhanced ultrasound in liver tumor Kai Li

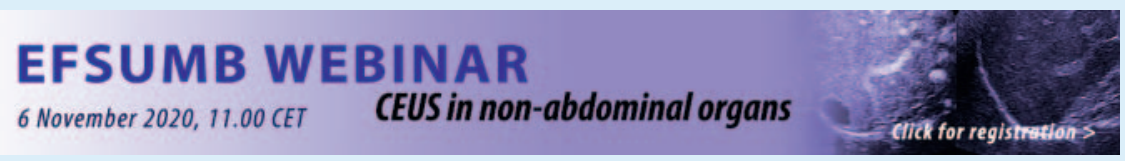

- value of CEUS applications in thyroid diseases Wen Luo

- Significance and value of CEUS in thyroid disease diagnosis and treatment Hong Yang

- Application of contrast-enhanced ultrasound in differential diagnosis of complex gynaecology masses Xinling Zhang

\section{EFSUMB Euroson Schools}

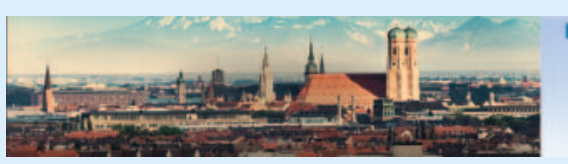

International Course in Contrast Enhanced Ultrasound Hepatic and Extrahepatic Indications EUROSON SCHOOL

Munich, Germany 14-17 October 2020

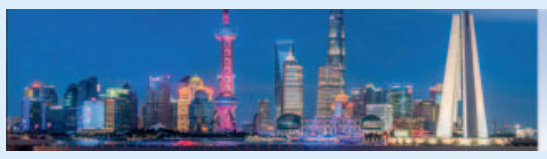

\section{CEUS Euroson School \\ EUROSON SCHOOL \\ Shanghai, China $\quad$ 20-21 November 2020}



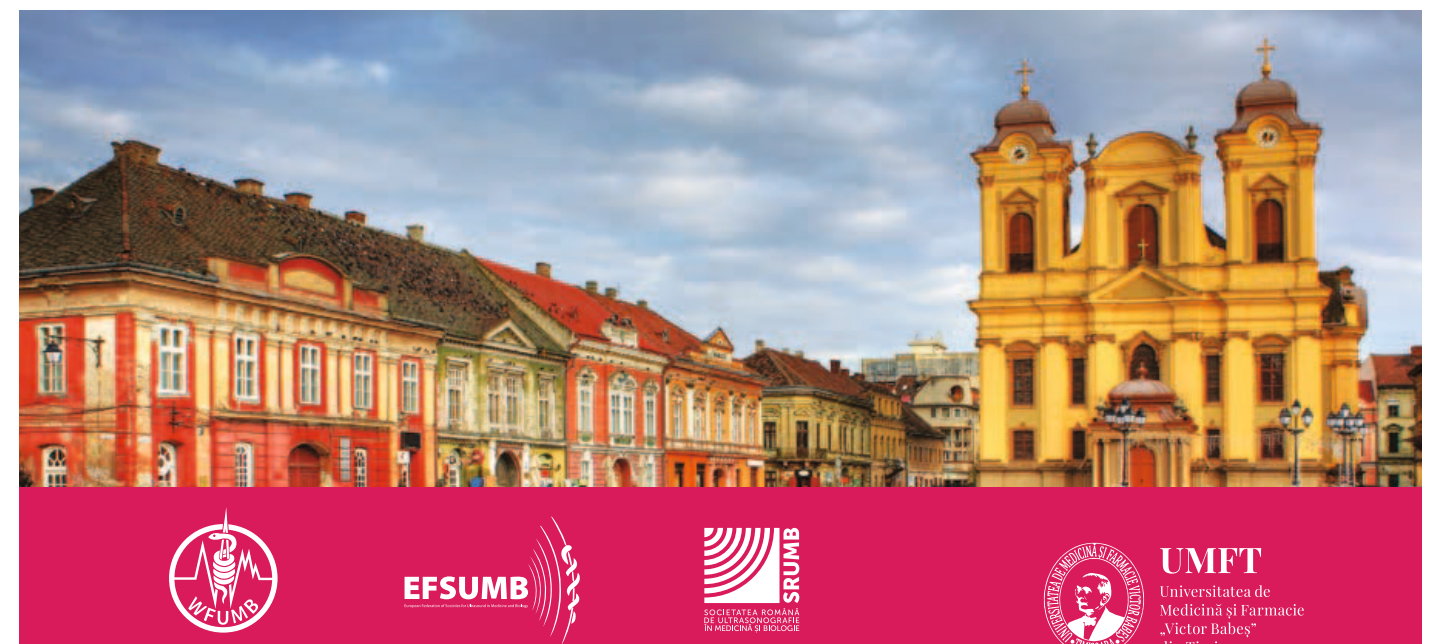

WFUMB 2021

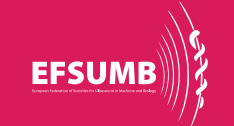

EUROSON 2021

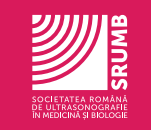

SRUMB 2021

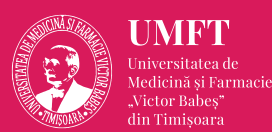

The $18^{\text {th }}$ World Federation for Ultrasound in Medicine and Biology Congress WFUMB 2021

The $33^{\text {rd }}$ Congress of European Federation of Societies for Ultrasound in Medicine and Biology EUROSON 2021

The $24^{\text {th }}$ National Conference of The Romanian Society of Ultrasound in Medicine and Biology SRUMB 2021

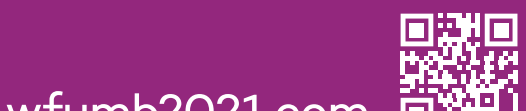

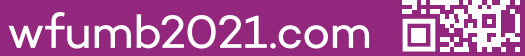

\section{MAY 26-29 2021}

Timișoara, Convention Center

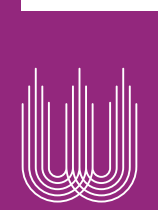

WFUMB CONGRESS 2021 TIMISSOARA

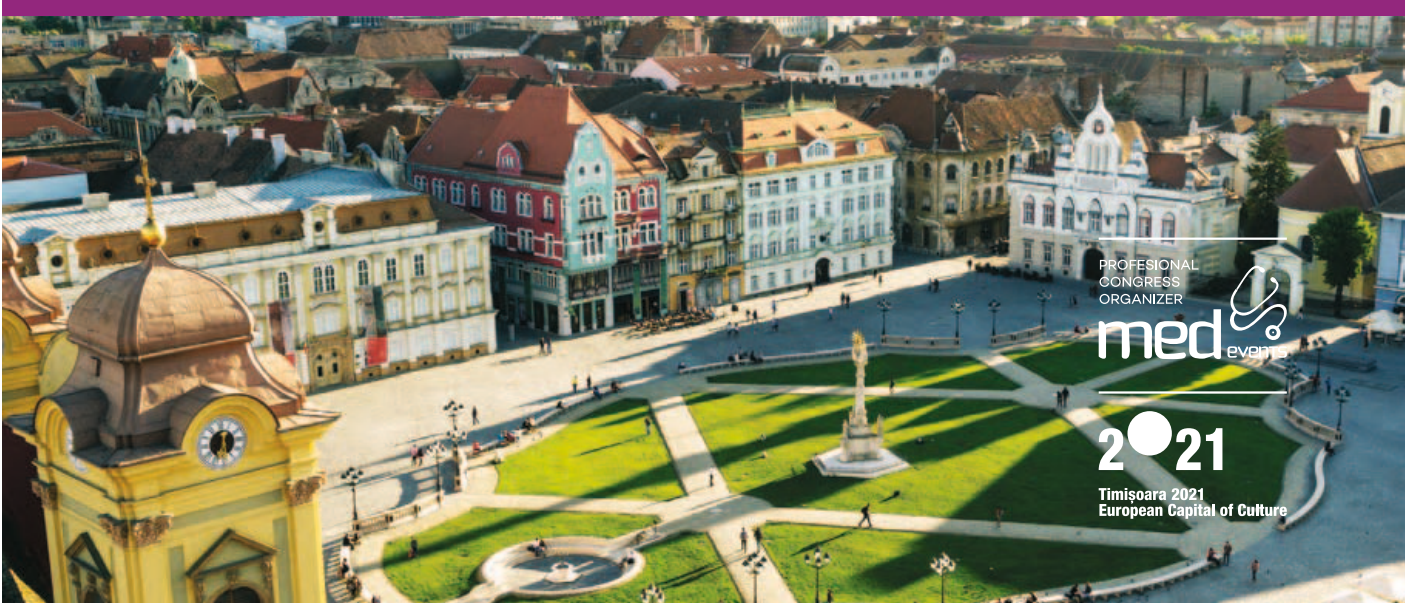


VENUE

TIMIŞOARA CONVENTION CENTER

Str Mărășești nr 1-3,

Timișoara, România

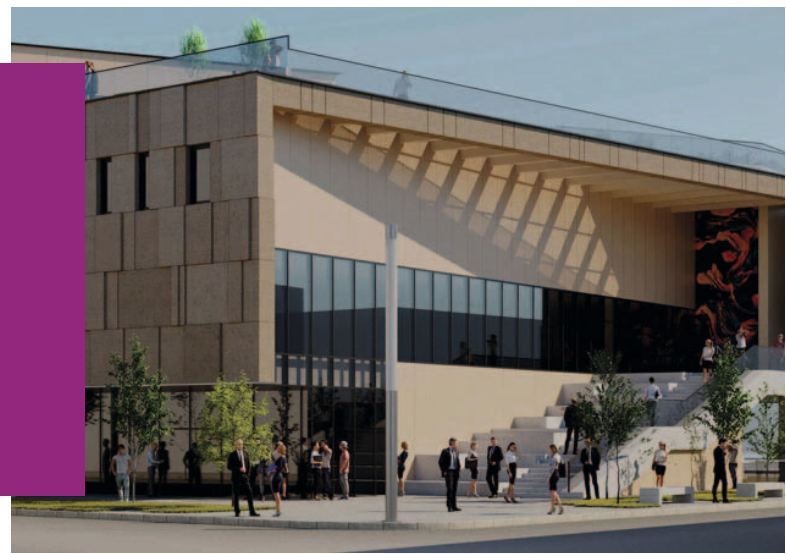

\section{SOME TOPICS AND HIGHLIGHTS}

\section{Postgraduate courses:}

- Point of care Ultrasound (POCUS)

- Ultrasound for the General Practitioner

- Emergency and Critical Care Ultrasound

- Breast Ultrasound

- Muskuloskeletal Ultrasound

- Vascular Ultrasound

- Ultrasound in Gynecology

- Echocardiography

\section{Other topics:}

- CEUS

- Elastography

- Ultrasound in Dermatology . EUS

- Ultrasound in Urology

- Neonatal and Pediatrics

- Gastrointestinal US
- Interventional US

- Head and Neck

\section{IMPORTANT DATES}

We are excited to announce that registration for the WFUMB 2021 congress will open on $\mathbf{1}^{\text {st }}$ of September 2020 on the website www.wfumb2021.com

20 JAN 2021

Deadline abstract submission
25 FEB 2021

Deadline early bird registration fee

\section{MAY 2021}

Deadline regular registration

\section{REGISTRATION FEES}

\begin{tabular}{llll} 
Registration type & $\begin{array}{l}\text { Early } \\
\text { registration } \\
\text { Before 25.02.2021 }\end{array}$ & $\begin{array}{l}\text { Regular } \\
\text { registration } \\
\text { Until 10.05.2021 }\end{array}$ & $\begin{array}{l}\text { On site } \\
\text { From 11.05 \& } \\
\text { On site }\end{array}$ \\
$\begin{array}{l}\text { WFUMB/EFSUMB/SRUMB member } \\
\text { (Proof of membership is required) }\end{array}$ & 300 Euro & 400 Euro & 600 Euro \\
\hline Non member & 450 Euro & 550 Euro & 700 Euro \\
\hline $\begin{array}{l}\text { Fellow in training (residents)/ } \\
\text { PhD students }\end{array}$ & 150 Euro & 250 Euro & 300 Euro \\
\hline $\begin{array}{l}\text { Medical Student } \\
\text { Only Wednesday or Thursday 30 Euro/day }\end{array}$ & 70 Euro & 70 Euro & 100 Euro \\
\hline \begin{tabular}{l} 
Sonographer \\
\hline
\end{tabular} & 200 Euro & 300 Euro & 400 Euro \\
\hline
\end{tabular}

